\title{
Apresentação \\ Os rumos do mundo rural na América Latina no início do século XXI, num cenário de grandes transformações sociais, econômicas e políticas
}

ANITA BRUMER*

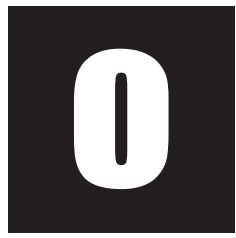

s trabalhos incluídos neste dossiê foram apresentados como conferências ou palestras (Simpósios) do VI Congresso da Associação Latino-Americana de Sociologia Rural (ALASRU), realizado em Porto Alegre, em novembro de 2002.

Na palestra de abertura, Diego Piñeiro, presidente da ALASRU no período 1998-2002, explicita a temática central do Congresso: "Sustentabilidade e democratização das sociedades rurais da América Latina". Ele mostra, por um lado, como os diversos programas econômicos seguidos pelos governos latino-americanos - tais como ajuste estrutural, desregulamentação estatal, privatização, abertura da economia a investimentos estrangeiros e abertura das fronteiras comerciais - em lugar de trazer maior bem-estar à população provocaram maior pobreza e intensificaram as desigualdades sociais. Por outro lado, a dívida externa desses países cresceu enormemente, impedindo a capitalização e o desenvolvimento econômico.

Como mostra Piñeiro, as grandes companhias multinacionais dominam cada vez mais os campos da biotecnologia, dos insumos para a agricultura e dos sistemas agro-alimentares. Controlam também a agricultura

* Professora-Doutora titular do Departamento de Sociologia, Instituto de Filosofia e Ciências Humanas, Universidade Federal do Rio Grande do Sul, Brasil. Endereço eletrônico: anita@orion.ufrgs.br. 
de exportação, sendo poucos os camponeses e os produtores familiares que puderam integrar-se ao processo e beneficiar-se com as mudanças tecnológicas e com o acesso aos mercados. Como conseqüência disso, diminuíram os empregos rurais e aumentou o número de trabalhadores que, embora mantendo residência no meio rural, trabalham nos setores industrial ou de serviços. Decorrem disso também os grandes movimentos de população, intra e entre países, em busca de emprego ou de melhores condições de garantir a subsistência.

Para Piñeiro, uma democracia plena só pode ocorrer caso se formule uma nova perspectiva de desenvolvimento: um desenvolvimento sustentável através do tempo, que não apenas busque o crescimento econômico mas também a justiça redistributiva e o pleno emprego, e que permita acesso igualitário aos direitos de cidadania, com ampla participação popular nos diversos níveis da sociedade. Além disso, isso somente terá sentido caso se preservem os recursos naturais para as gerações futuras, "sustento material insubstituível de todo bem-estar".

$\mathrm{Na}$ primeira das quatro conferências proferidas no Congresso da ALASRU, José Bengoa faz uma abrangente retrospectiva das transformações ocorridas nas sociedades rurais da América Latina nos últimos 25 anos, assinalando como elas refletiram-se nos temas e métodos de análise adotados pelos sociólogos rurais preocupados com sua análise e interpretação.

Como mostra o autor, em seu artigo, nos anos 1960 e 1970, promover o desenvolvimento rural era sinônimo de promover a modernização do campo. A partir de um ponto de vista essencialmente urbano, graças ao qual o campo era visto como atrasado, deprimido e deprimente, a reforma agrária era considerada como a solução capaz de liberar os camponeses do império do latifúndio. Contrariamente a isso, as reformas realizadas em vários países latino-americanos, de um modo geral, tiveram efeitos práticos devastadores sobre a estrutura agrária e sobre a vida rural, e a agricul- 
Sociologias, Porto Alegre, ano 5, no 10, jul/dez 2003, p. 14-25

tura da região continua sem resolver problemas tais como a concentração da terra, as condições de trabalho às quais são submetidos os trabalhadores rurais e a qualidade de vida de camponeses e indígenas. Sintomaticamente, nos últimos 10 anos, os sociólogos rurais praticamente não mais examinam a tendência modernizadora da agricultura latino-americana, mas tratam de compreender como os diferentes casos locais se dimensionam, adequam, integram e resistem face a esta modernização.

Bengoa sintetiza os principais direcionamentos das mudanças ocorridas na região (e nas pesquisas) em cinco aspectos: (1) deslocamento da fazenda - caracterizada, até os anos 1970, pela relação estreita (e indestrutível) entre produção e poder, economia e poder local, propriedade da terra e política - para a empresa moderna exportadora, resultando na desvinculação dos estudos sobre a agricultura dos estudos sobre o mundo rural; (2) deslocamento da questão camponesa para as questões referentes à pobreza rural; (3) mudança nos sistemas de trabalho e nos assentamentos humanos, com o deslocamento da servidão dos camponeses sem terra nas fazendas, para o trabalho temporário, o que provocou o aumento de sua precariedade e vulnerabilidade; (4) de uma problemática centrada nos camponeses, em decorrência dos movimentos sociais, em meados dos anos 80 começou a emergir a questão indígena; (5) da centralização nos camponeses, em conseqüência dos movimentos feministas também iniciados nos anos 80, passaram a ser visualizados camponeses e camponesas, vindo à tona uma problemática particular das mulheres rurais.

O autor finaliza seu texto destacando o poder simbólico do rural, graças ao qual o rural é visto como sociedade diferenciada, como fonte e força simbólica e identitária para as sociedades que se encaminham a um processo de globalização acelerado.

O texto de Carmen Diana Deere e Magdalena León incluído neste dossiê aborda temática semelhante à do livro "O empoderamento da Mulher: direitos à terra e direitos de propriedade na América Latina", publicado em inglês (University of Pittsburgh Press, 2001), espanhol (Tercer 
Mundo Editores e Facultad de Ciencias Humanas, Colombia, 2000) e português (Editora da UFRGS, 2002). Neste artigo, apresentado por Magdalena León numa conferência, durante o congresso da ALASRU, as autoras ampliam a apresentação de dados, incluindo dois novos países da América Latina, além de acrescentar novas perspectivas analíticas.

O argumento central do texto é a idéia de que, na América Latina, o alcance da igualdade formal, com base na legislação, no que diz respeito aos direitos de propriedade, não implicou necessariamente numa igualdade de fato entre homens e mulheres. A discrepância manifesta-se principalmente na preferência dada aos homens no acesso à propriedade da terra, que é mediado por uma série de interferências culturais, políticas e econômicas, fortemente arraigadas na família, no Estado e no mercado, que têm como conseqüência a preferência dada aos filhos varões no processo de herança, a privilégios masculinos no casamento, a uma tendência ao favorecimento dos homens nos programas estatais de distribuição da terra e à tendenciosidade de gênero na participação no mercado de terras, onde as mulheres têm menos chance do que os homens de atuar como compradoras. Além disso, homens e mulheres tendem a adquirir terras de maneiras distintas: a principal forma das mulheres tornarem-se proprietárias de terras é através de herança, enquanto que a aquisição de terras é um importante meio de acesso para os homens.

As autoras demonstram que a propriedade da terra é crucial para o empoderamento das mulheres, sobretudo quando se leva em conta a relação entre propriedade de bens e a capacidade de negociação na família e na comunidade.

A conferência de Afrânio Garcia, intitulada "Hierarquias sociais e os legados da escravidão: mobilizações camponesas e democratização do espaço público", da mesma forma que a apresentação de José Bengoa, faz uma retrospectiva das questões sociais rurais, embora com ênfase na situação brasileira. 
O autor centra suas reflexões nas condições sociais de possibilidade do individualismo moderno, entendendo que em sua gênese está o surgimento da cidadania política, formulada como a concepção "do indivíduo portador de desejos e senhor de seus atos para sua concretização".

Contrariamente às idéias que perpassam o discurso liberal ou neoliberal - de que, para que os indivíduos possam se exprimir livremente, basta eliminar as restrições de tipo estatal ou burocráticas - o autor destaca a importância das condições históricas e sociais da existência na conformação das possibilidades de atuação dos indivíduos.

Para demonstrar esta idéia, Garcia mostra como, na história do século XX, o legado da escravidão ou de formas de subordinação pessoal acarretadas nas grandes plantações dos engenhos e usinas brasileiros ou por instituições como a encomienda tem um grande impacto sobre a sociabilidade hierárquica herdada da época colonial e das possibilidades de exercício da cidadania política, em áreas rurais da América Latina. Para Garcia, o exame do processo histórico brasileiro mostra que "a experiência da liberdade vem associada, para a maioria da população, à vivência de um empobrecimento material que limita, evidentemente, os investimentos culturais e de desenvolvimento da subjetividade".

Garcia mostra ainda como, no decorrer do século XX, se dá a quebra das condições da existência da dominação tradicional, as várias modalidades de desenraizamento do campesinato e a presença em grande escala do 'indivíduo por falta' (por carência), destacando as origens sociais do movimento dos sem terra e os futuros alternativos do mundo rural. Como indica o autor, é importante observar que o 'mundo agrícola', atualmente, não é mais um bloco coeso. "A representação do mundo agrícola, a imagem de unicidade que se buscava no início do século, é hoje atravessada pela oposição dos agentes concebidos por categorias como 'agricultura familiar', 'complexo agro-industrial', 'agricultura empresarial', 'agricultura tradicional', a demonstrar a intensidade da competição por terra, por recursos financeiros, por força de trabalho e, sobretudo, pela legitimidade de designar o futuro das relações no mundo rural e das configurações cidade-campo". 
Em sua conferência, Alessandro Bonanno considera as características principais do processo de globalização do sistema de produção de alimentos, em relação com o desenvolvimento econômico da América Latina. Inicia mostrando as principais posições existentes em torno do processo de globalização, para depois examinar, com base em estudos de caso, nos Estados Unidos, três questões originadas nesse debate: o funcionamento do livre mercado, a força e o papel do Estado, e a questão da democracia.

No primeiro caso estudado, o autor verificou que o mercado, em vez de ser livre, está fortemente condicionado pelas atividades das companhias multinacionais, as quais exercem pressões que possibilitam tanto a manipulação da informação disponível no 'mercado livre' como evitar controles por parte dos consumidores, dos investidores e das instituições estatais. Fica claro, em sua análise, que o mercado é fortemente condicionado pelas companhias multinacionais e que suas ações afetam negativamente vários grupos sociais. O Estado mantém poderes importantes, embora eles estejam sendo usados para incrementar os interesses das companhias multinacionais, ao criar condições para uma enorme mobilidade do capital.

No segundo caso, a decisão das companhias multinacionais de investir na região estudada com uma agroindústria de suínos demonstra a super mobilidade do capital global, tendo em vista sua busca por condições de produção, clima político e estruturas sociais que lhes são mais convenientes. Entre essas condições estão: (1) um esforço por parte das elites políticas locais para criar condições favoráveis para atrair investimentos externos para, supostamente, gerar desenvolvimento econômico; (2) a existência de uma baixa densidade populacional, que facilita a falta de reação popular a práticas agrícolas que gerem fortes cheiros desagradáveis, contaminem o ar com pó tóxico e as fontes de águas potáveis com uma emissão abundante de excrementos animais; (3) a existência de regras brandas para a proteção do meio-ambiente, que viabilizem este tipo de produção sem criar uma oposição política excessiva; (4) a localização da região nas proxi- 
Sociologias, Porto Alegre, ano 5, no 10, jul/dez 2003, p. 14-25

midades de outros estados, possibilitando às empresas multinacionais estimular a competição entre eles: se um estado não cumpre com as exigências das companhias multinacionais, novos investimentos são deslocados para outro estado, nas proximidades, onde o clima social, econômico e político lhes sejam mais favoráveis.

No terceiro caso, Bonanno focaliza a instalação de uma agroindústria avícola numa região norte-americana, onde houve forte resistência da população. A análise realizada pelo autor permitiu demonstrar que: (1) processos de globalização podem provocar resistências mesmo em situações em que a comunidade não tinha originalmente posições anti-globalização; (2) na ausência de estruturas sociais mobilizadoras da cidadania no processo de tomadas de decisões, fortes movimentos populares não têm garantias de que suas ações sejam levadas em consideração; (3) a falta de estruturas ou sistemas sociais para facilitar a participação popular salienta um dos limites mais importantes do neoliberalismo: as estruturas de mercado e sobretudo as relações sociais que se desenvolvem num sistema de mercado não dão a grupos subalternos (ou a aqueles que não estão incluídos nos circuitos globais) possibilidades reais de participar em processos políticos. Como resultado, a questão da democracia torna-se um dos problemas mais importantes da globalização.

Cristóbal Kay examina as relações entre estrutura agrária, conflitos e violência rural na América Latina, tomando como ponto de referência dados do Chile, Peru, Colômbia, Brasil, México e alguns países da América Central. Em todos esses países, a violência rural manifesta-se na morte em conflitos e assassinatos de um número muito grande de pessoas e do deslocamento de importantes contingentes populacionais, tendo como ponto central o problema da terra.

Apesar de considerar que a violência rural tem causas múltiplas e apresenta aspectos diferenciados conforme o país, o autor argumenta que esta violência tem suas raízes no sistema agrário baseado na desigualdade e na exclusão. Como mostra Kay, um dos principais motivos para os confli- 
tos e para a violência rural é a demanda por terra, as tentativas frustradas de acesso a ela (via reforma agrária) - como a falta dos governos em cumprir suas promessas de distribuição de terras e/ou outorgar apoio econômico e técnico suficiente ao setor reformado - e a reação violenta dos grandes proprietários territoriais. "As reformas agrárias com freqüência provocaram violência pela frustração do campesinato na lentidão, perspectiva limitada e estruturação de cima-para-baixo do programa de reforma". Por outro lado, quando alguns governos começaram a distribuir mais terras, os latifundiários organizaram-se para bloquear a reforma agrária e, em alguns casos, tiveram a capacidade de derrotar o governo e recuperar em parte ou no todo as terras que haviam sido expropriadas, utilizando-se com freqüência de meios violentos, seja diretamente com base em pistoleiros contratados ou organizações paramilitares, seja apoiando-se no poder repressivo do Estado.

A aplicação das reformas neo-liberais na América Latina nos anos 1990 provocou o aumento das desigualdades e o inchamento das camadas pobres e indigentes em praticamente todos os países do continente. Como mostra Norma Giarraca, uma das conseqüências das políticas implantadas foi o aumento das tensões, conflitos, movimentos e protestos sociais. $\mathrm{Na}$ Argentina, país sobre o qual a autora centrou sua análise, os protestos ocorridos nos anos 1990 se 'desterritorializaram' (isto é, ocorreram em todo o país e não apenas nos centros urbanos industriais), começando a descolarse dos mundos rurais e de baixa urbanização. Esses protestos foram promovidos por atores sociais com baixa visibilidade política pública na história das lutas sociais do país até então - tais como desocupados, indígenas, camponeses, mulheres agricultoras, entre outros - e ocorrem em torno de terra, trabalho, moradia e saúde. Dizem respeito a direitos adquiridos nos processos democratizadores do século XX (tais como condições de trabalho, salários dignos, educação pública, acesso à saúde, entre outros) e em risco de serem perdidos em seu final; a preservação de pequenos patrimônios familiares (ameaçados pelo elevado endividamento); a demanda por uma renda 
Sociologias, Porto Alegre, ano 5, no 10, jul/dez 2003, p. 14-25

mínima face à perda de trabalho remunerado. Como mostra a autora, 'são protestos de 'defesa' e 'preservação' face ao avanço das políticas 'expropriadoras' do neoliberalismo.

Entre os agricultores, as demandas se basearam em 'políticas econômicas e defesa das economias regionais', enquanto que os indígenas buscavam fundamentalmente direitos e acesso à terra e os trabalhadores agrícolas e agroindustriais pediam melhores salários e condições de trabalho.

Como mostra a autora, 'enquanto que o setor agrário se convertia, para o governo, no espaço do qual ele podia extrair recursos, devido a suas vantagens relativas no comércio internacional (soja, basicamente), as demandas dos camponeses desalojados por novos investidores, das unidades produtivas endividadas e dos operários agroindustriais despedidos com freqüência não eram consideradas pelas autoridades estatais; e, por outro lado, não conquistaram as simpatias das populações urbanas envolvidas em seus próprios conflitos'. 'Voltaram a circular demandas sociais agrárias num contexto em que o campo se ia convertendo, de acordo com o dispositivo comunicativo do poder agrário-exportador, no grande salvador da nação. Os povos se empobreceram e os números de pobreza, fome e indigência alcançaram cifras impensáveis no outrora 'graneiro do mundo'.

Regina Bruno focaliza seu artigo nos grandes proprietários rurais, examinando a violência patronal como uma prática de classes durante o período iniciado com a redemocratização do Brasil, em 1985, após 20 anos de ditadura militar. De acordo com Bruno, "dois principais traços marcam o perfil das classes e grupos dominantes no campo: a defesa da propriedade como direito absoluto e a violência como prática de classe". Trata-se de uma violência ritualizada e institucionalizada, que inclui a formação de milícias, a contratação de capangas e os massacres. Da mesma forma, esta violência procura anular a importância dos trabalhadores rurais, de seus mediadores e de suas reivindicações. Como expressa a autora, "tão descarregadora quanto a violência física é a desqualificação dos trabalhadores rurais e de seus mediadores veiculada pelos proprietários e 
empresários rurais, no exercício da dominação política".

No que se refere ao posicionamento dos integrantes das classes dominantes do campo quanto à reforma agrária, de acordo com Bruno, os "proprietários de terra e empresários rurais consideram inadmissível a defesa, pelo governo, de uma reforma agrária como política social. Eles argumentam que, na atual conjuntura, um discurso pautado pelo social inevitavelmente abrirá espaço para a discussão sobre o uso social da terra e poderá legitimar, perante a sociedade, a desapropriação como instrumento prioritário da reforma". Eles também questionam a real capacidade dos trabalhadores rurais na condução política da reforma agrária. Quanto mais próximos às cadeias agroindustriais estão esses produtores, mais intensa é a desqualificação que eles fazem dos trabalhadores rurais; estes são vistos como "bons de enxada", mas incapazes de se transformar em "proprietários e produtores autênticos".

Finalizamos o dossiê com o texto "Agricultura familiar e o novo mun-

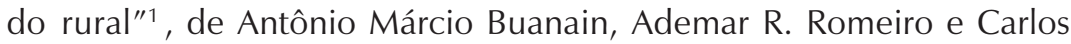
Guanziroli. O trabalho insere-se na perspectiva analítica do 'Novo Mundo Rural $^{\prime},{ }^{1}$ de certa maneira liderada por José Graziano da Silva, e que gerou diversas teses de doutoramento e muitos artigos e livros sobre as temáticas da pluriatividade, da urbanização do rural e do que foi denominado de 'rurbano'. Os autores do trabalho procuram polemizar com os pesquisadores integrantes do grupo grazianista, contrapondo-se à idéia de oposição entre o futuro da agricultura familiar e o que vem sendo caracterizado como 'novo mundo rural', como se um excluísse o outro. Para eles, "não se trata de negar que essas 'novas' atividades vêm ganhando espaço, mas de perguntar se este fato, por si só, é suficiente para negar que o desenvolvimento com equidade no meio rural brasileiro ainda passa pelo fortalecimento da agricultura familiar".

Os autores consideram que, "para grande parte da população econo-

\footnotetext{
1 Este é o único texto incluído no dossiê deste número de Sociologias que não foi apresentado no Congresso da ALASRU, no final de 2002. Sua apresentação ocorreu no Congresso da Sociedade Brasileira de Economia Rural e Sociologia Rural (SOBER), realizado alguns meses antes, e foi enviado à comissão editorial da revista Sociologias por seus autores, com vistas a sua eventual publicação. A decisão de publicá-lo aqui decorreu de sua apreciação favorável sobre a relevância dos dados e análises apresentados.
} 
Sociologias, Porto Alegre, ano 5, no 10, jul/dez 2003, p. 14-25

micamente ativa na agricultura, a expansão, nos anos 1980, dos empregos rurais não-agrícolas representa não uma ampliação das oportunidades de trabalho para os membros da família tornados supérfluos pelo progresso técnico, mas sim uma chance de sobrevivência, em geral precária, para produtores sem acesso ao progresso técnico, à terra suficiente e ao crédito". Eles procuram demonstrar que "quando recebe apoio suficiente, o produtor familiar é capaz de produzir uma renda total, incluindo a de autoconsumo, superior ao custo de oportunidade do trabalho".

Uma das conclusões possibilitada pela análise de dados é que o universo dos produtores familiares é bastante diversificado. No entanto, de acordo com os autores, de um modo geral os estudos confirmam que em todas as regiões a agricultura familiar explora de forma intensiva os recursos escassos disponíveis, existindo a possibilidade de geração de níveis de renda agropecuária superiores ao nível de reprodução da família. $\mathrm{Na}$ sua perspectiva, se este potencial nem sempre se realiza, isso ocorre devido às severas restrições de recursos enfrentadas pelos agricultores familiares, particularmente na Região Nordeste, ou devido às condições macroeconômicas negativas e à ausência ou deficiência das políticas públicas. "Historicamente a agricultura familiar enfrentou um quadro macroeconômico adverso, caracterizado pela instabilidade monetária e inflação elevada (...), descriminação negativa da política agrícola que favorecia os produtores patronais, política comercial e cambial desfavorável e deficiência dos serviços públicos de apoio ao desenvolvimento rural. Na realidade, ao invés de promover o desenvolvimento rural e local, o conjunto de políticas públicas promoveu o esvaziamento do campo e inibiu o desenvolvimento local em favor das grandes metrópoles e cidades médias".

Em seu conjunto, os textos apresentados neste dossiê chamam a atenção para as enormes desigualdades socioeconômicas existentes na América Latina, em seu caráter de exclusão de grandes parcelas da população, de lutas sociais em que se embatem trabalhadores sem terra e latifundiários, sob 
a mediação do Estado, e de estratégias de grandes produtores e empresários para a manutenção de seus privilégios. Alguns autores salientaram o fato de que sociedades com maior equidade na distribuição dos recursos e menor grau de exclusão econômica e social - incluindo o acesso à terra e a igualdade de gênero e de raça (etnia) - são as que apresentam menor grau de violência (tanto física como simbólica). Cabe ao Estado, através da formulação e da implementação de políticas públicas, um papel importante na solução dos conflitos e da violência rurais, no favorecimento dos pequenos produtores rurais, no estabelecimento de uma maior equidade de gênero, na inclusão social de indígenas e negros, na limitação do poder dos grandes latifundiários e empresários e na defesa dos interesses gerais das sociedades atuais e futuras na preservação do meioambiente.

\section{Resumo}

O artigo apresenta nove textos que integram o dossiê sobre sustentabilidade e democratização das sociedades rurais da América Latina, publicados neste número da Revista Sociologias. Esses textos (com uma exceção) foram apresentados no Congresso da Associação Latino-Americana de Sociologia Rural, realizado em Porto Alegre em novembro de 2002, e ilustram a variedade temática e atualidade dos conteúdos das pesquisas sociológicas sobre a agricultura e o meio rural do continente latino-americano.

Palavras-chave: Sociologia rural, democratização, sustentabilidade, conflitos. 